\title{
Influence of exposure to high muscularity bodies on muscularity preferences and body satisfaction in young men.
}

\author{
Jaques, K.* \& Hanson, L.* \& Boothroyd \\ University of Durham, South Road, Durham, DH1 3LE< UK \\ *These authors contributed equally.
}

\section{Keywords:}

\begin{abstract}
The visual diet hypothesis suggests that exposure to a certain body type increases our preference for that type of body, and exposure to ideal bodies is proposed to lead to body dissatisfaction. Here we examined the effect of exposure to high/low muscularity bodies on muscularity preferences and, subsequently, on body satisfaction in men, as well as exploring how men's pre-existing cognitions around their bodies might moderate susceptibility to these effects. Study 1 participants ( 80 women, 84 men) viewed high or low muscularity images of real and CGI male bodies and reported their preferences for pairs of bodies varying in muscularity before and after. They additionally completed the Sociocultural Attitudes Towards Appearance Questionnaire 4. Data replicated previous results showing that viewing low muscularity images reduces preferences for muscularity in participants. This was significantly moderated by SATAQ in men, such that those with higher internalisation of cultural body ideals (higher SATAQ scores) showed this effect more strongly. In Study 2, participants ( $81 \mathrm{Men}$ ) completed the same task, with the change that some viewed the CGI bodies, and some the real bodies, during the manipulation, and also completed the Drive for Muscularity Scale at pre-test and the Body Image States Scale at pre- and post-test. Results again showed that exposure to low muscularity bodies reduces muscularity preferences but there was no moderating effect of SATAQ or of drive for muscularity. There was also no impact of viewing the images on body satisfaction.
\end{abstract}

\section{Introduction}

\section{Body Image}

Body Image Dissatisfaction (BID) is an issue whereby individuals perceive their own body to be in some way different from the body size or shape they wish to have and feel emotional dissatisfaction or distress at that discrepancy (Cash, Morrow, Hrabosky, \& Perry, 2004). For women, their desired body is often thinner than their current body, in line with the hyper-thin ideal presented by Western media (Ball \& Dittmar, 2011; Boothroyd, et al., 2016; Juarascio, et al., 2011), while men aspire for a more muscular body (Grossbard, Neighbors, \& Larimer, 2011; Lane, Mulgrew, White, \& Mahar, 2019; Thornborrow, Onwuegbusi, Mohamed, Boothroyd, \& Tovee, 2020). BID emerges early in girls (Evans, 2012; Evans, et al., 2017) and is prevalent in both sexes by puberty, with $24-80 \%$ of early adolescent girls (Bornioli, Lewis-Smith, Smith, Slater, \& Isabelle, 2019; Dion, et al., 2015; Lawler \& Nixon, 2011; Stice \& Whitenton, 2002) and 14-54\% of boys (Bornioli et al., 2019; Dion, et al., 2015; 
Lawler \& Nixon, 2011) expressing dissatisfaction. This number only increases through adolescence, with around $70-80 \%$ of university-aged men and women expressing BID (Cramblitt \& Pritchard, 2013; Dakanalis, et al., 2015; Spitzer, Henderson, \& Zivian, 1999). This high percentage of individuals reporting BID is concerning as BID is related to low self-esteem and depression (Barlett, Vowels, \& Saucier, 2008), disordered eating (Ferrer-Garcia \& Gutierrez-Maldonado, 2012), excessive exercise (Dawson \& Hammer, 2020), and future health-risking behaviours such as smoking, gambling, and substance misuse (Bornioli et al., 2019).

Internalisation of Western body ideals is proposed as a key risk factor for BID, and crosscultural studies have found that exposure to Western media increases preferences for slimmer female bodies (Boothroyd et al., 2016; Boothroyd et al., 2019; Swami et al 2010) in both sexes, and increases risk of eating disorders in women (Becker, Verzijl, Kilpela, Wilfred, \& Stewart, 2019) and drive for muscularity in men (Thornborrow, Onwuegbusi, Mohamed, Boothroyd, \& Tovee, 2020). Internalisation of cultural body ideals can be caused by viewing still images such as in magazines (Stice, Spangler, \& Agras, 2001) or moving images such as on TV (Bair, Kelly, Serdar, \& Mazzeo, 2012), or can be due to perceived pressure from family and peers to obtain an ideal body (Cafri, Yamamiya, Brannick, \& Thompson, 2006). However, these studies highlight that individuals most affected by media influences tended to be vulnerable individuals who already had high thin-ideal internalisation (Bair et al., 2012; Stice et al., 2001).

Boothroyd et al. (2012) found that exposure to large or small female bodies resulted in a subsequent shift in body size preferences in women, regardless of whether those bodies were appealing to the viewer or not. They argued that an individual's 'visual diet' (their consumption of perceptual information regarding bodies) can influence an internal prototype of the 'average' body, against which all bodies viewed or preferred are calibrated, meaning that the ideal is constantly shifting based on what body types are being viewed most. The visual diet hypothesis has been supported for perceptions of body weight attractiveness (Boothroyd, et al., 2020), what participants consider a healthy vs unhealthy weigh body (Robinson \& Kirkham, 2014), and desirability to look a certain way (Cramblitt \& Pritchard, 2013).

\section{Male Body Image and Muscularity}

The study of body image has historically focussed on female bodies, as they were assumed to face more pressure from Western culture to conform to body ideals than men (Frith \& Gleeson, 2004). However, in the last twenty years the literature has expanded to include the study of male body image and the pressures they face to conform to the Western ideal of a lean, well-toned, muscular physique portrayed in Western media (Cordes, Vocks, Dusing, Bauer, \& Waldorf, 2016; Cramblitt \& Pritchard, 2013). It has also been shown that men's ideal body tends to have between $8-13 \mathrm{~kg}$ more muscle mass than their current body (Cramblitt \& Pritchard, 2013; Litt \& Dodge, 2008), suggesting there is a large discrepancy between the muscular ideal and how muscular men perceive themselves to be. Additionally, most studies have found that higher media consumption is related to internalisation of the muscular ideal, however the direction of the relationship was unclear. Thornborrow et al. (2020) considered men in three different cultures with varying levels of media exposure and found that Ugandan men, who had the lowest levels of Western media consumption, had a significantly less muscular ideal than men in the UK, and that more TV viewing was associated with a more muscular ideal and lower general body satisfaction. These findings support the visual diet hypothesis and 
highlight the negative effects of Western media consumption on internal body ideals and body satisfaction.

Western body ideals are also linked to gender norms and masculinity, and men who internalise the muscular ideal tend to also internalise traditional gender roles (De Jesus, et al., 2015). This joint internalisation is common across Western cultures, including countries considered to be advanced in gender equality (Gattario, et al., 2015). This link between gender roles and muscular physique can be seen in all Western media; muscular characters in top grossing action films released between 1980-2006 were more likely to be romantically involved, more aggressive, had more positive outcomes, and were more likely to experience objectification than less muscular characters (Morrison \& Halton, Buff, tough, and rough: Representations of muscularity in action motion pictures, 2009); action figures have been gaining a significant amount of muscularity since the 70 s to the point that some of their physiques were impossible to obtain, even for professional body builders (Pope, Olivardia, Gruber, \& Borowiecki, 1999); and in advertising, men in adverts in 2009 were significantly more muscular than men in adverts ten years previous (Jung, 2011), and muscular men are portrayed as 'refined and sophisticated' across cultures (Tan, Shaw, \& Ko Kim, 2013), suggesting that high muscularity is shown as aspirational and is associated with high status in society (Jacques, submitted). Boothroyd et al. (2012) propose that as well as visual diet influencing what is considered normal, achievable, and attractive, we associate high muscularity with good health and high socioeconomic status through associative learning mechanisms, and that both influences may act in parallel. Therefore, the wealth of information portraying masculinity and muscularity as desirable can lead to internalisation of these ideals through the visual diet hypothesis and associative learning mechanisms, and when ideal muscularity is not achieved, this can lead to negative outcomes such as BID, disordered eating (Lane, Mulgrew, White, \& Mahar, 2019), and health-risking behaviours such as steroid use (Litt \& Dodge, 2008).

Jones and Crawford (2005) found that body image issues develop in boys between the ages of 13 and 16, with older boys reporting more body-focussed discussion with peers. Additionally, boys with a high BMI were more likely to report weight concerns and dieting behaviours while boys with a lower BMI reported wanting to build more muscle. This pattern of results was mirrored by Ricciardelli and McCabe (2001), who found that adolescent girls all reported wanting to have a thinner body, while adolescent boys were divided, with some wanting a thinner body and some wanting a bigger body, suggesting body image ideals are more complex in boys than girls. One explanation for this differing pattern of results is that men internalise both the muscular ideal and the thin ideal. Klimek et al. (2018) found that muscular and thin ideal internalisation were independently associated with disordered eating and muscle dysmorphia, and that internalisation of muscular ideals without also internalising thin ideals was associated with more severe muscle dysmorphic symptoms than men who internalised both or neither. The authors theorise this could be due to muscles being harder to see when body fat percentage is higher. Internalisation of the drive for thinness may also be due to differing muscular ideals possibly indicating a desire for a slim and lean body rather than a large bulky body. McCreary and Sasse (2000) found that adolescent boys who took part in sports where a slim body was beneficial reported more drive for thinness than those who desired a hyper-muscular and physically bulky body. However, a review found that male university students reported their ideal figure as being significantly more muscular than their current figure, but not significantly thinner (Grossbard, Neighbors, \& Larimer, 2011), suggesting that while a small proportion may want a slim and lean body, a significant majority wish to be more muscular. 
Men's visual attention upon viewing own and other men's bodies has been found to focus on the upper body, most frequently the chest (30-35\% of visual attention) and abdomen (20-25\% of visual attention), suggesting these regions are most relevant for male body image (Cordes, Vocks, Dusing, Bauer, \& Waldorf, 2016). Additionally, men were found to focus more on 'attractive' regions when viewing other men's bodies (average 900 milliseconds). However, this study used men who had an average of 4 years of weight training and attended gyms regularly, therefore these men may have had increased drive for muscularity compared to men who do not regularly attend gyms for weight training, and may not be a representative sample. Additionally, men who regularly attend the gym will have a visual diet of other gym goers which may bias their internal ideal towards slim and muscular figures. Exposure to advertisements containing muscular men has been shown to reduce own-body satisfaction while exposure to non-muscular men caused no significant change in body satisfaction (Lorenzen, Grieve, \& Thomas, 2004). Another study found that exposure to both muscular and slender advertisements caused a decrease in body satisfaction with no significant differences between conditions (Galioto \& Crowther, 2013). However, the authors suggest that since the adverts contained attractive male models whose faces and advertised products were visible that this decrease in body satisfaction may have been due to associative learning mechanisms and not necessarily visual diet. This seems likely given the significant effect of social comparison and media internalisation on preand post-exposure body satisfaction in this study, highlighting that men who have internalised the Western ideal and tend to compare themselves to others had initially lower body satisfaction scores and were more vulnerable to viewing idealised images.

\section{Attitudes Towards Muscularity}

BID has been shown to develop due to a number of factors such as personal attitudes towards muscularity and pressure from external sources such as the media, family, or peers (Edwards, Molnar, \& Tod, 2017; McCabe \& Ricciardelli, 2003). Since these are shown to influence internalisation of the muscular ideal, it is important to consider how these might interact with exposure to muscular or nonmuscular bodies and any changes in muscularity preferences or body satisfaction which occur. In young adults, peer and family pressures have been found to be especially salient and act as a risk factor for development of BID (Jones \& Crawford, 2005), and low perceived social support and negative body talk have been found to reinforce internalisation of media ideals (Ata, Ludden, \& Lally, 2007; Jones \& Crawford, 2005; Stanford \& McCabe, 2005). In a qualitative study, men discussed how negative body related comments and pressure from fathers and peers in childhood were particularly salient in the development of BID and drive for muscularity, as well as experiences of bullying (Edwards, Molnar, \& Tod, 2017). Additionally, they discussed 'activating events' which occurred in late adolescence or early adulthood which prompted either an increase or decrease in drive for muscularity, with negative social events such as a breakup leading to increased drive for muscularity. This highlights the importance of sociocultural factors on internalisation and reinforcement of media ideals and own-body satisfaction; however, the role sociocultural pressure might play in changing muscularity preferences and body satisfaction after short-term exposure to muscular or non-muscular bodies is not known.

An individual's drive for muscularity is linked to internalisation of media ideals whereby individuals have a strong desire to achieve a muscular body which resembles the ideal shown by the media. High drive for muscularity has been shown to be predictive of short-term use of steroids (Litt \& Dodge, 2008), BID (Cramblitt \& Pritchard, 2013), excessive exercise (Pritchard, Parker, \& Nielsen, 2011), and disordered eating (Lavender, Brown, \& Murray, 2017). Development of drive for 
muscularity has been linked to long-term exposure to the muscular ideal in magazines (Harrison \& Bond, 2007) and television (Cramblitt \& Pritchard, 2013), but its effect on changes in muscularity preferences and body satisfaction after short-term exposure to muscular or non-muscular images is not known.

\section{Stimuli}

Across studies it is not always clear whether reported effects are due to visual diet, associative learning mechanisms, a combination of both, or something else entirely. This is in part due to some differences in study design, primarily the stimuli used. Studies have used silhouette drawings to determine differences in perceived and ideal bodies (Duchin et al., 2015; Grossbard, Neighbors, \& Larimer, 2011; Lai et al., 2013; Lawler \& Nixon, 2011; Ricciardelli \& McCabe, 2001), pictures of real bodies (Cordes, Vocks, Dusing, Bauer, \& Waldorf, 2016; Lorenzen, Grieve, \& Thomas, 2004; Mo et al., 2014; Robinson \& Kirkham, 2014), pictures of CGI bodies (Cazzato et al., 2016; Cazzato, Siega, \& Urgesi, 2012; Cornelissen, McCarty, Cornelissen, \& Tovee, 2017; Groves et al., 2019; Matthews, Lynch, \& Martins, 2016; Thornborrow et al., 2020), or a combination (Jacques, submitted). While this may not be the most significant cause of discrepancies in results between studies, effects of differences in stimuli type should be investigated to determine how much it may influence the results. Additionally, variances in pose, lighting, skin tone, visibility of face, and other factors may all influence how the body is perceived. It is therefore important to determine in stimuli type has any influence on visual diet manipulations resulting in changes in muscularity preferences or body satisfaction.

\section{Current Studies}

The current studies are conducted with the aim to improve our understanding of muscularity in body image. Study 1 aims to determine whether certain individuals are more susceptible to visual adaptation effects in the muscularity dimension over others. We first hypothesise that exposure to muscular images would increase preference for those images and vice versa. Our second hypothesis states that individuals who experienced high sociocultural pressure to adhere to cultural body norms would be more susceptible to these adaptation effects.

Study 2 aims to replicate and extend these findings by including an individual's drive for muscularity and state body image. First, we hypothesise that, as in Study 1, exposure to muscular bodies will increase muscularity preferences and decrease state body satisfaction (and vice versa). Secondly, perceived sociocultural pressure will predict susceptibility to adaptation effects and changes in muscularity preferences and state body satisfaction. Thirdly, drive for muscularity will influence change in muscularity preferences and state body satisfaction after exposure to muscular bodies. Finally, we aim to explore the effect of stimuli type on adaptation effects.

\section{Study 1}

\section{Method}

\section{Ethics}

Ethical approval was gained from Durham University's Psychology Department Ethics Committee. Participants were asked to provide consent before the trials began by clicking a box to confirm they had read and understood the information sheet and privacy notice. Participants were 
shown the debrief statement once they had completed all trials and were provided with a web link to a popular body image support website.

\section{Participants}

The study was conducted remotely online and participants were recruited from Durham University's departmental participant pool, word of mouth and snowball sampling. 165 (80 male, 84 female and 1 'other') participants were recruited, with an average age of 19 and most participants stating their sexual orientation as 'heterosexual'. Participants were counterbalanced into one of two manipulation conditions.

\section{Sociocultural Attitudes Towards Appearance Questionnaire - 4 (SATAQ-4; Schaefer et al., 2015)}

Participants completed the SATAQ prior to other measures. The SATAQ-4 contains 22 items split into four subscales concerning internalisation of media ideals (e.g. "I think a lot about looking muscular"), pressure from family (e.g. "Family members encourage me to get in better shape"), pressure from peers (e.g. "My peers encourage me to get thinner"), and pressure from the media (e.g. "I feel pressure from the media to improve my appearance") to obtain and maintain an idealised body. Items are forward scored on a 5-point Likert-style scale from 'definitely disagree' to 'definitely agree' where a high average score indicates more perceived pressure to be thin/muscular. This questionnaire has been shown to have good reliability and validity (Barra, Roberto da Silva, Maroco, \& Campos, 2019; Schaefer et al., 2015).

We also measured body satisfaction using a one-item measurement of body satisfaction: 'Overall, how dissatisfied are you with your body from '1- Very Dissatisfied' to '7-Very Satisfied'?'.

\section{Preference for muscularity task}

Following completion of the SATAQ-4 questionnaire, participants completed the first preference for muscularity task. The preference stimuli (12 CGI images of male bodies varying in muscle mass) were created using DAZ Studio 4.10, using the 'Genesis 2 Base Male' in basic white briefs. 6 high muscle mass and 6 low muscle mass versions of this body were created in total. Each high muscle mass CGI image was randomly paired with a low muscle mass CGI image, creating 6 trials in total.

Participants were presented with 6 pairs of CGI images (presented one pair at a time) and were asked to indicate which image from each pair they preferred and the extent to which they preferred it using an 8 point slider scale from 'strongly prefer left body' (low muscle mass body) to ' 7 strongly prefer right body' (high muscle mass body), with the muscular body presented to the right hand side for half of all trials and the left hand side for the remaining trials in a randomised order. An example preference task trial is shown in Figure 1. Overall muscularity preference scores for the premanipulation preference task were generated by averaging the preference scores for each of the 6 trials. A high average score indicated a preference for high muscle mass male bodies whilst a low score indicated a preference for low muscle mass male bodies. Participants were asked to complete this preference task again following the manipulation phase to assess whether their preference for muscularity had changed following manipulation. 


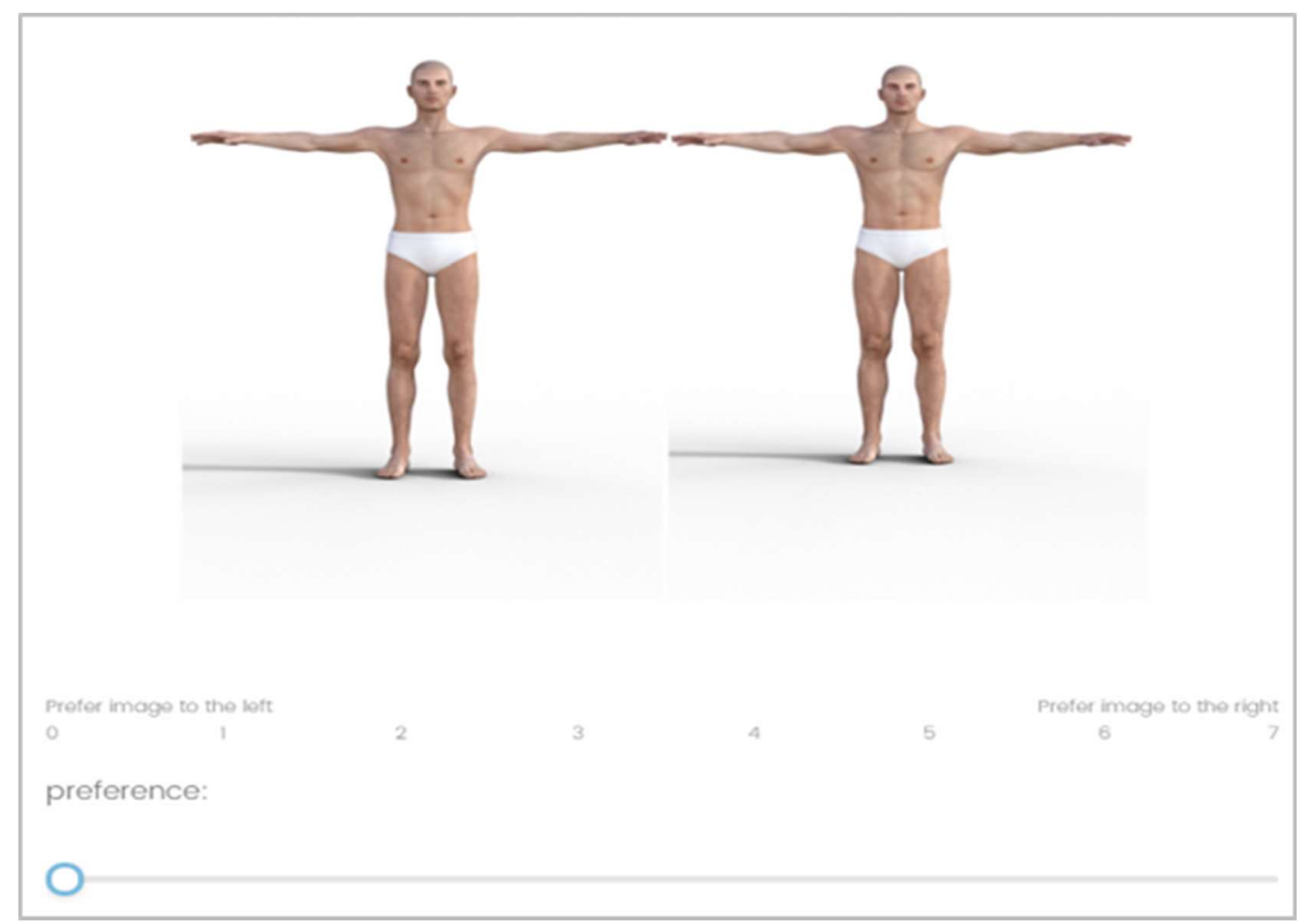

Figure 1. Example trial from the pre-and post- manipulation preference task.

\section{Manipulation phase}

Participants were told the manipulation phase of the study was designed to further explore body preferences. They were shown a series of images (presented individually) and were asked to compare each new image presented to the image previously seen whilst indicating which one they found the most attractive (for the first manipulation phase image presented, participants were asked to compare it to the last viewed pre-manipulation preference phase image). The order of presentation was fully randomised and the purpose of asking participants to indicate preferences during this phase was simply to keep participants focused on the stimuli presented. Participants were allocated to one of the 4 manipulation conditions on the basis of their birth month.

81 (38 male and 43 female) participants were allocated to Condition 1 and viewed 48 low muscle mass male bodies. 84 (42 male and 41 female and 1 'other') participants were allocated to Condition 2 and viewed 48 muscular male bodies.

The manipulation images included a mixture of photographs and CGI images of low muscle mass (Condition 1) and high muscle mass (Condition 2) males presented in a randomised order. The CGI images were those individual images used in the preference for muscularity trials (6 high and 6 low muscle mass). Each CGI image was presented twice and in mirror-image form to create 24 low muscle mass (Condition1) and 24 high muscle mass (Condition 2) manipulation CGI images. The photographs were open access images retrieved from Morrison, Wang, Hahn, Jones and DeBruine (2017). These photographs consisted of 24 low muscle mass (Condition 1) and 24 low muscle mass (Condition 2) photographs of nude males, with bodies in a standard anatomical position (standing with arms out to the side, legs apart and facing the camera straight on) with faces and genitals obscured. 
These images were pre-rated for muscularity (on a scale of 0 -10) using a sample of 1518 -year-old students ( 6 males and 9 females) and were then grouped accordingly ( $\geq 6 / 10=$ high muscle mass image and $\leq 4 / 10=$ low muscle mass image).

Following the manipulation phase, participants were told that they needed to complete the second half of the preference task. This involved completing the same preference task as was required during the pre-manipulation preference for muscularity task. Following this final phase of the study, participants were thanked for their participation and shown the debrief statement.

\section{Results}

Descriptive statistics for participants are shown in Table 1. Men and women showed similar levels of internalisation (SATAQ-4) but men had slightly stronger preferences for muscularity than women.

Table 1. Tabulated baseline correlations for all variables measured at pre-manipulation.

\begin{tabular}{lllll} 
Mean & $\begin{array}{l}\text { Standard } \\
\text { Deviation }\end{array}$ & 1 & 2 & 3 \\
\hline
\end{tabular}

\section{All Participants}

1. Age $\quad 19.76 \quad 2.76$

$\begin{array}{lllll}\text { 3. SATAQ-4 } & 2.96 & 0.59 & -.00 & .23^{* *}\end{array}$

$\begin{array}{llllll}\text { 4. Muscularity } & 4.70 & 1.24 & .18^{*} & .35^{* *} & .18^{*}\end{array}$

Preference

Men

1. Age $\quad 19.84 \quad 2.59$

$\begin{array}{llll}\text { 2. BMI } & 20.11 & 3.19 & .24\end{array}$

$\begin{array}{lllll}\text { 3. SATAQ-4 } & 2.98 & 0.62 & .02 & 32 * *\end{array}$

$\begin{array}{lllll}\text { 4. Muscularity } & 5.25 & 0.92 & .06 & .20\end{array}$

.20 .13

Preference

\section{Women}

\begin{tabular}{|c|c|c|c|c|}
\hline 1. Age & 19.68 & 2.93 & & \\
\hline 2. BMI & 17.94 & 2.38 & .06 & \\
\hline 3. SATAQ-4 & 2.95 & 0.56 & -.03 & .12 \\
\hline $\begin{array}{l}\text { 4. Muscularity } \\
\text { Preference } \\
p<.05,{ }^{* *} p<.01\end{array}$ & 4.18 & 1.28 & $.27^{*}$ & $.27^{*}$ \\
\hline
\end{tabular}


Data were entered into linear mixed models in R (Bates, Maechler, Bolker, \& Walker, 2015; R Core Team, 2020) where participant was a random effect, and time and image and muscularity condition were entered as fixed effects. Model results are shown in Table 2. There was a significant interaction between time and muscularity condition, such that preference for high muscle mass male bodies tended to decrease following exposure to low muscle mass manipulation images as demonstrated in Figure 2. Paired comparison on participants in each condition showed that the effect of time was significant in both cases (Low: $p<.001$, High: $p=.002$ ). Adding gender and its interactions to the model did not change these results and there was no effect of gender itself on preferences (see Table 2.)

Table 2. Linear model fixed effect results for muscularity preferences, showing model estimates, $S E$, $t$-value, and $p$-value for each term. Participant entered as a random factor.

Model 1

\begin{tabular}{|c|c|c|c|c|c|c|c|c|}
\hline & $\beta$ & SE & $\mathbf{t}$ & p & $\beta$ & SE & $\mathbf{t}$ & $\mathbf{p}$ \\
\hline (Intercept) & 4.65 & 0.10 & 47.84 & $<.001$ & 5.16 & 0.14 & 40.29 & $<.001$ \\
\hline Time & -0.10 & 0.06 & -1.62 & 0.105 & -0.17 & 0.08 & -2.04 & 0.042 \\
\hline Muscularity & 0.40 & 0.20 & 2.05 & 0.041 & 0.52 & 0.27 & 2.03 & 0.042 \\
\hline Gender & & & & & -0.99 & 0.19 & -5.55 & $<.001$ \\
\hline $\begin{array}{l}\text { Time : } \\
\text { Muscularity }\end{array}$ & 0.63 & 0.12 & 5.33 & $<.001$ & 0.75 & 0.17 & 4.50 & $<.001$ \\
\hline Time : Gender & & & & & 0.14 & 0.12 & 1.22 & 0.224 \\
\hline $\begin{array}{l}\text { Muscularity : } \\
\text { Gender }\end{array}$ & & & & & -0.29 & 0.38 & -0.80 & 0.422 \\
\hline $\begin{array}{l}\text { Time : } \\
\text { Muscularity : } \\
\text { Gender }\end{array}$ & & & & & -0.24 & 0.24 & -1.03 & 0.305 \\
\hline
\end{tabular}

\section{Model 2}




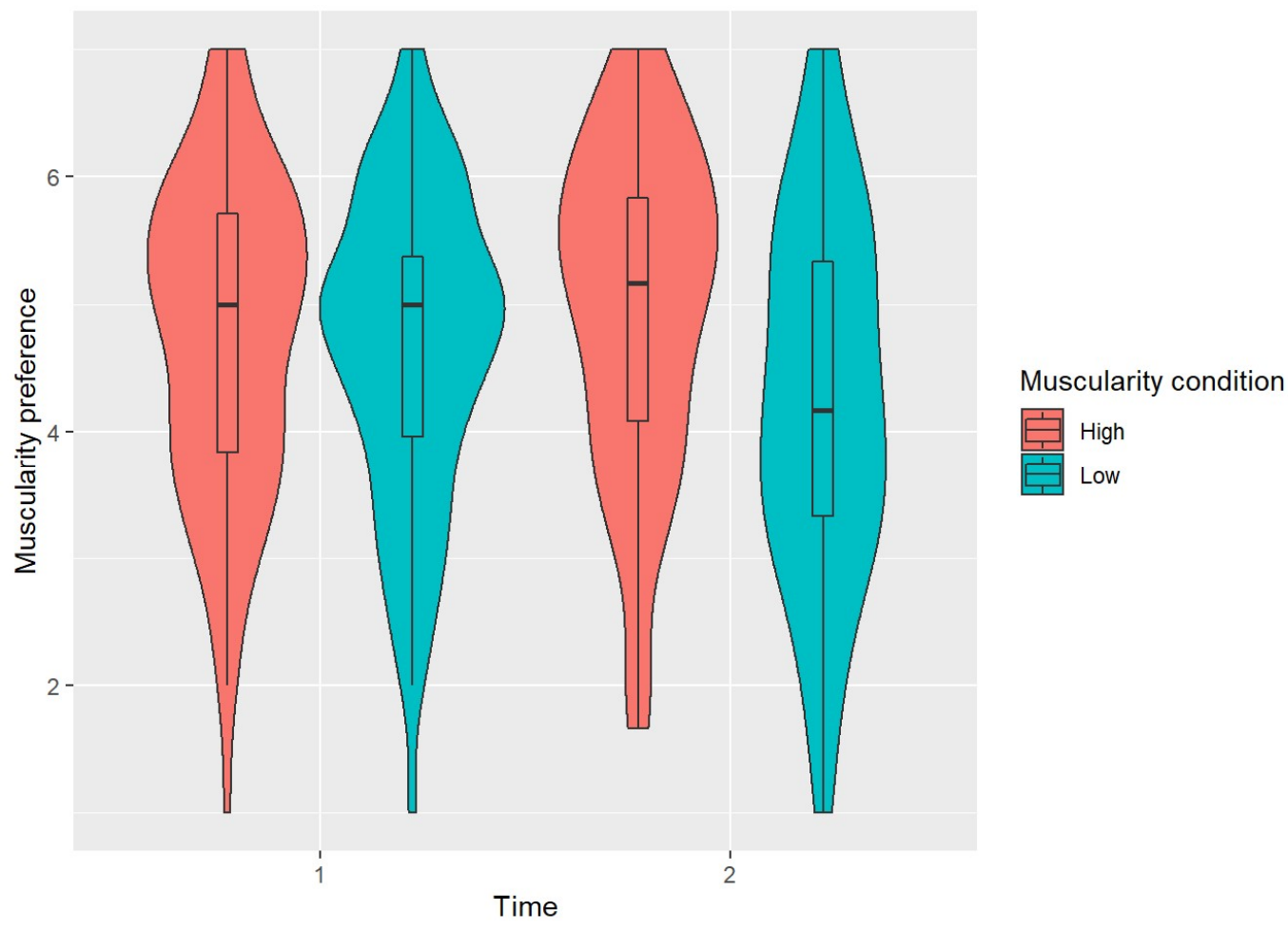

Figure 2. Preference for muscularity score for the pre-and post-manipulation preference phases for each of the experimental conditions.

We then analysed the effect of SATAQ on these results in the 80 males in the sample. Repeating the mixed effect model with SATAQ and the 3-way interaction term (time by condition by SATAQ) added, showed a significant interaction effect $(B=0.028, S E=0.011, p<.05)$. The median SATAQ-4 score was 3.09. To explore the interaction, data were median-split on SATAQ scores; males with a SATAQ-4 score of $>3.09$ (higher cultural ideals internalisation) $(\mathrm{N}=39)$ showed a significant interaction between time and condition $(B=1.17, S E=.243, p<.01)$. For those below the mean $(N=41)$ however, the interaction was no longer significant $(B=.37, S E=.213)$. As shown in Figure 3 , the higher men's SATAQ scores, the more likely they were to show a negative change in their muscularity preferences after viewing low-muscularity images. 


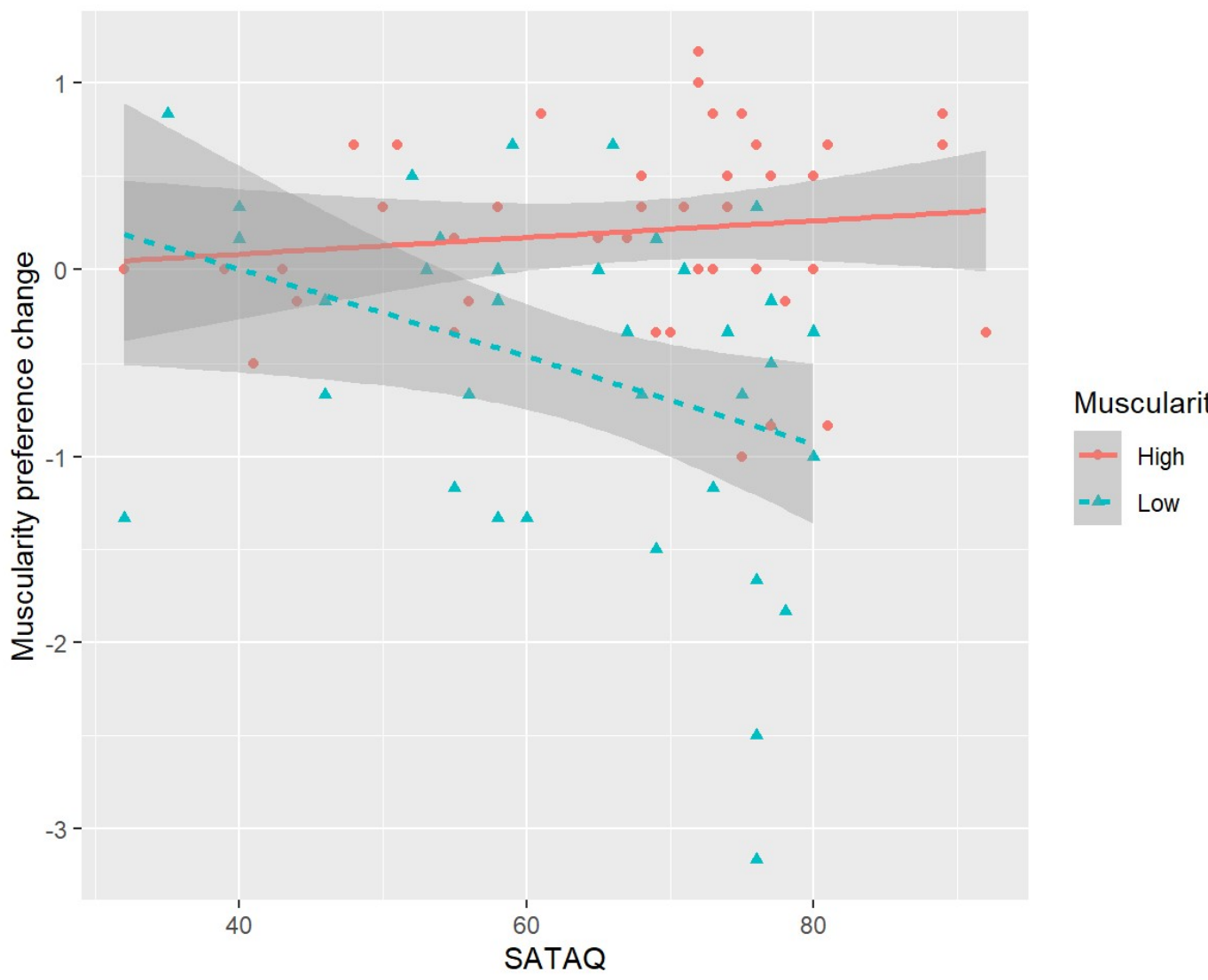

Figure 3. Change in muscularity preferences (pre-test minus post-test) regressed onto SATAQ scores in each condition. Shading shows confidence interval.

\section{Interim Discussion}

The purpose of this study was to explore whether certain individuals were more susceptible to visual adaptation effects in the muscularity dimension over others. We predicted that those who were most dissatisfied with their bodies would be more susceptible to such adaptation effects. Overall, findings suggest that viewing muscular (non-muscular) male bodies increased (decreased) preferences for muscular (non-muscular) bodies as predicted. In terms of enhanced susceptibility to such adaptation effects, we found that internalisation of cultural body ideals does predict susceptibility to the visual adaptation effect in the muscularity dimension in men. However, we would note that as shown in Figure 3, there were a small number of men with high SATAQ scores, and big shifts in their preferences who were potentially exaggerating this effect and so replication is essential.

\section{Study 2}

\section{Introduction}

Study 2 was conducted with the purpose of replicating and extending the results of Study 1. There are several methodological differences which will help us to further our understanding of the results from Study 1. Firstly, Study 2 included several measures which were not included in Study 1; 
namely the Drive for Muscularity Scale and the Body Image States Scale. These were used to determine if an individual's drive for muscularity influenced their susceptibility to the manipulation effect, and to see if viewing muscular and non-muscular images had any effect on state body image in addition to altering muscularity preferences. Secondly, only males between the ages of 18-30 were recruited for this study, in order to focus on the effects of muscularised images on younger men in particular. Finally, in Study 1, stimuli were split into high or low muscle mass but included both real and CGI generated images. In order to ascertain whether these images had any effects on the results Study 2 split the stimuli into 4 categories, high/low muscle mass and real/CGI image and showed each participant only one combination (e.g. high muscularity CGI bodies only).

The visual diet hypothesis would suggest that exposure to muscular (non-muscular) bodies would increase (decrease) preference for muscular bodies and decrease (increase) state body satisfaction. As such, the aim of Study 2 was to discover if men's muscularity preferences and BID changed after exposure to muscular or non-muscular bodies, and to explore if stimuli type, drive for muscularity, or perceived sociocultural pressure influence this effect. From this, we can draw three hypotheses. First, we hypothesise that exposure to muscular bodies will increase muscularity preferences and decrease state body satisfaction (and vice versa). Secondly, perceived sociocultural pressure will interact with time and condition to influence change in muscularity preferences and state body satisfaction after exposure to muscular bodies. Thirdly, drive for muscularity will interact with time and condition to influence change in muscularity preferences and state body satisfaction after exposure to muscular bodies. Finally, since there has been no research on the effect of stimuli type on the effects of exposure to muscular or non-muscular bodies, we can make no predictions about the type or severity of changes in muscularity preferences or body satisfaction.

\section{Method}

Ethics

The study was approved by the Durham University Psychology Department Ethics Committee. Participants were asked to provide consent before the study began by clicking a box to confirm they had read and understood the information sheet and privacy notice. After the study participants were shown a debrief sheet and were provided with web links and phone numbers to body image support charities and the University counselling service. They were also provided with the lead researcher's email should they have any questions.

\section{Participants}

Participants were 81 men after exclusions. The age range was 18-30 with a mean (standard deviation) of 22.98 (3.06). Participants provided their height and weight from which their BMI was calculated. The BMI range was 17-34 with a mean (standard deviation) of 23.4 (3.69) indicating that most of the participants were within the healthy range (NHS, 2018). They were recruited through advertising and given no compensation for their time. Participants were excluded if they did not identify as male $(n=16)$, were under $18(n=1)$, or over $30(n=4)$. This reduced the number of participants from 102 to 81 .

Participants were told that the aim of the experiment was to explore body preferences and that the study would last between 10 and 20 minutes. 

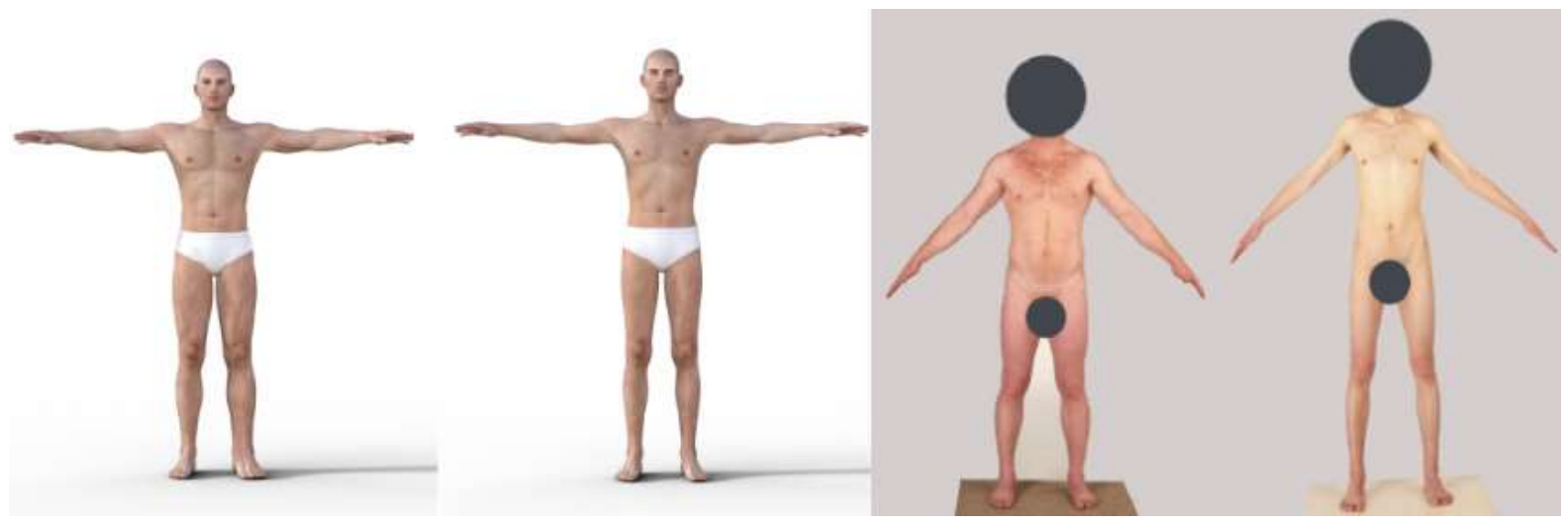

Figure 4. Examples of stimuli used in the study. Far left: High muscle mass CGI. Centre left: Low muscle mass CGI. Centre right: High muscle mass real. Far right: low muscle mass real.

\section{Materials and Stimuli}

Participants were directed to follow a link which took them directly to the study hosted on the 'Qualtrics' website. The study could be run on most devices which have internet access and a screen to view the questionnaire. Participants complete the SATAQ as above, followed by:

Drive for Muscularity Scale (DMS; McCreary \& Sasse, 2000)

The DMS is a 15-item scale which is rated from 1 (Always) to 6 (Never). All items are forward scored and low average scores indicate a high drive for muscularity. There is some debate around the inclusion of item 10 ("I think about taking anabolic steroids") as it does not load onto either of the two factors identified from the scale (Muscularity-oriented body image and Muscularity behaviour; McCreary, Sasse, Saucier \& Dorsch, 2004), but the questionnaire is significant when including or excluding this item (DeBlaere \& Brewster, 2017) so it was included in this study. In testing it showed good reliability and validity (McCreary, Sasse, Saucier, \& Dorsch, 2004; McPherson, McCarthy, McCreary, \& McMillan, 2010; see Appendix B for full questionnaire).

Body Image States Scale (BISS; Cash et al., 2002)

The BISS is a 6-item scale which measures state body image. Each question begins "Right now I feel" and is followed by 9 options (e.g. "extremely satisfied with my body size and shape" "extremely dissatisfied with my body size and shape"). It contains three forward- and three reversecoded items and a high average score indicates higher body satisfaction. Participants completed this questionnaire twice, once before the manipulation and once after. In testing it has been shown to have good reliability and validity (Cash, Fleming, Alindogan, Steadman, \& Whitehead, 2002).

\section{Preference for muscularity task}

The preference stimuli (12 CGI images of male bodies varying in muscle mass) were created using DAZ studio 4.10, using the 'Genesis 2 Base Male' in basic white briefs. 6 high muscle mass and 6 low muscle mass versions of this body were created in total. The high muscle images were randomly paired with the low muscle mass images prior to inclusion in the study, creating 6 muscularity preference trials which were presented in a random order immediately before and after the manipulation phase. A high average score indicates preference for a more muscular body (See Fig. 1).

\section{Manipulation Phase}


CGI stimuli (Condition 1 and 2) were the same as in the pre-manipulation preference task. Real stimuli were open-access images retrieved from Morrison, Wang, Hahn, Jones and DeBruine's (2017) paper. All manipulation images fell under the fair use consideration of copyright legislation at the time of study. All manipulation images were pre-rated for muscularity (on a scale of 0 -10) using a sample of 15 18-year-old students ( 6 males and 9 females) and were then grouped accordingly ( $\geq 6 / 10=$ high muscle mass image and $\leq 4 / 10=$ low muscle mass image). Participants were randomly allocated into one of four conditions. 18 participants saw 24 high muscle mass CGI bodies, 22 participants saw 24 low muscle mass CGI bodies, 19 participants saw 24 high muscle mass real bodies, and 22 participants saw 24 low muscle mass real bodies (see Fig 4).

\section{Procedure}

After signing the consent form, participants were first presented with demographic questions regarding their age, gender, height, and weight, then filled out the SATAQ-4, DMS, and BISS. Participants the completed the preference task and adaptation phase, followed by the muscularity preference task and BISS for a second time. They were then thanked for their time, presented with a debrief from, and given the contact details of the main researcher in case of any further questions.

\section{Results}

Linear mixed effect models were used to test for possible effects of manipulation condition, sociocultural attitudes and drive for muscularity on muscularity preferences and body image. Analyses were conducted using R version 3.6.3 (R Core Team, 2020), with Ime4 version 1.1-21 (Bates, Maechler, Bolker, \& Walker, 2015). The dependent variables were muscularity preference score and BISS score. Table 3 shows tabulated baseline correlations between variables.

Table 3. Tabulated baseline correlations for all variables measured at pre-manipulation.

\begin{tabular}{lllllll} 
Variable & Mean & $\begin{array}{l}\text { Standard } \\
\text { Deviation }\end{array}$ & $\mathbf{1}$ & $\mathbf{2}$ & $\mathbf{3}$ & $\mathbf{4}$ \\
\hline 1. Age & 22.98 & 3.06 & & & \\
2. BMI & 23.40 & 3.69 & -.01 & & \\
3. DMS & 4.21 & 0.88 & .08 & .00 & & \\
4. SATAQ-4 & 2.70 & 0.64 & -.08 & .15 & $-.44^{* *}$ & \\
$\begin{array}{l}\text { 5. Muscularity } \\
\text { Preference }\end{array}$ & 4.98 & 1.14 & .03 & $.23^{*}$ & $-.44^{* *}$ & $.24 *$ \\
$*_{p<.05, * * p<.01}^{*}$ & & & & & &
\end{tabular}

\section{Effect of condition and stimuli on muscularity preferences and body image}

A linear mixed effect model was conducted where the dependent variable was muscularity preference and the predictors were time (pre/post manipulation), muscularity (high/low muscle mass images), and their interaction. There was a significant interaction between time and muscularity (see Table 4). 
Table 4. Mixed model effects of time, muscularity, and stimuli on muscularity preferences.

Model 1

(Intercept)

Time

Muscularity

Time :

Muscularity

Stimuli

Time : Stimuli

Muscularity :

Stimuli

Time :

Muscularity :

Stimuli

0.51

$\begin{array}{llllllll}\boldsymbol{\beta} & \text { SE } & t & p & \boldsymbol{B} & \text { SE } & t & p\end{array}$

Model 2

$4.92 \quad 0.13 \quad 37.80<001$

4.92

$0.13 \quad 37.52<.001$

$0.10 \quad-1.15 \quad .251$

$-0.11$

$\begin{array}{lll}0.10 & -1.13 & .258\end{array}$

$0.26 \quad 0.91 \quad .366$

0.23

$\begin{array}{lll}0.26 & 0.88 & .379\end{array}$

$0.19 \quad 2.63$

.009

0.52

$0.19-2.65$ .008

$\begin{array}{llll}0.16 & 0.26 & 1.61 & .544\end{array}$

$\begin{array}{llll}-0.28 & 0.19 & -1.43 & .153\end{array}$

$\begin{array}{llll}0.42 & 0.52 & 0.79 & .427\end{array}$

$\begin{array}{llll}0.04 & 0.39 & 0.09 & .928\end{array}$

This suggests that muscularity condition significantly influences muscularity preferences after viewing muscular or non-muscular bodies. Pairwise comparisons indicated that there was a significant effect of time for the low muscularity condition $(\beta=-0.37, S E=0.13, p=.003)$, but not for the high muscularity condition ( $p=.339$; see Fig 5 ). 


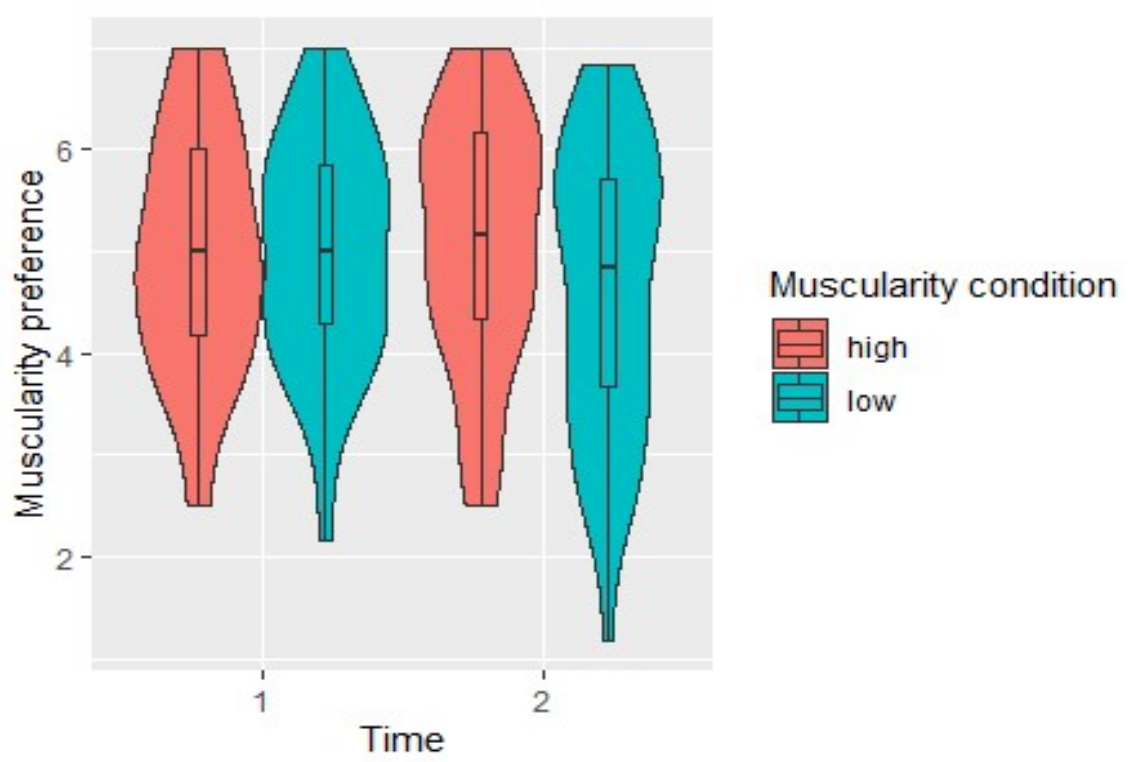

Figure 5. Violin plot showing the mean muscularity preference at pre- (Time 1) and post- (Time 2) manipulation for high muscularity (red) and low muscularity (blue) conditions.

We next ran a similar set of models with BISS as the dependent variable. There were no significant main effects or interactions in either model (see Table 5). This suggests that viewing high or low muscularity bodies does not directly influence personal body image.

As there were no significant main effects or interactions for stimuli, it was not included in further analyses (see Tables 5 \& 6).

Table 5. Mixed model effects of time, muscularity, and stimuli on body satisfaction (BISS)

\begin{tabular}{|c|c|c|c|c|c|c|c|c|}
\hline & \multicolumn{4}{|c|}{ Model 1} & \multicolumn{4}{|c|}{ Model 2} \\
\hline & $\boldsymbol{\beta}$ & SE & $\mathbf{t}$ & $\mathbf{p}$ & $\beta$ & SE & $\mathbf{t}$ & $\mathbf{p}$ \\
\hline (Intercept) & 5.20 & 0.18 & 28.88 & $<.001$ & 5.20 & 0.18 & 28.60 & $<.001$ \\
\hline Time & -0.06 & 0.09 & -0.67 & .503 & -0.06 & 0.09 & -0.69 & .490 \\
\hline Muscularity & -0.01 & 0.36 & -0.04 & .971 & -0.01 & 0.36 & -0.03 & .975 \\
\hline Time : Muscularity & 0.30 & 0.18 & 1.68 & .093 & -0.31 & 0.18 & -1.70 & .088 \\
\hline Stimuli & & & & & 0.09 & 0.36 & 0.26 & .798 \\
\hline Time : Stimuli & & & & & 0.29 & 0.18 & 1.59 & .112 \\
\hline Muscularity : Stimuli & & & & & -0.45 & 0.73 & -0.62 & .536 \\
\hline Time : Muscularity : Stimuli & & & & & -0.10 & 0.36 & 0.27 & .788 \\
\hline
\end{tabular}




\section{Effect of perceived sociocultural pressure on muscularity preferences and body image}

Mixed linear effect models were used to determine if perceived sociocultural pressure measured by the SATAQ-4 influences muscularity preferences or personal body image after viewing high or low muscle mass images. In the first model, the dependent variable was muscularity preferences and the predictors were time (pre/post manipulation), muscularity (high/low muscle mass images), SATAQ-4 score, and their interactions.

There was a significant main effect of SATAQ-4 for this model.

The second model used BISS as the dependent variable, with time, muscularity, SATAQ-4, and their interaction as predictors. In this model, there was a significant main effect of SATAQ-4 (see Table 6).

Table 6. Mixed model effects of time, muscularity, and SATAQ-4 on muscularity preferences (Model 1), and body satisfaction (Model 2)

\begin{tabular}{|c|c|c|c|c|c|c|c|c|}
\hline & \multicolumn{4}{|c|}{ Model 1: Muscularity preferences } & \multicolumn{2}{|c|}{ Model 2: BISS } & \multirow[b]{2}{*}{$\mathbf{t}$} & \multirow[b]{2}{*}{$\mathbf{p}$} \\
\hline & $\beta$ & SE & $\mathbf{t}$ & $\mathbf{p}$ & $\beta$ & SE & & \\
\hline (Intercept) & 3.66 & 0.56 & 6.49 & $<.001$ & 7.74 & 0.75 & 10.35 & $<.001$ \\
\hline Time & -0.13 & 0.10 & -1.31 & .189 & -0.06 & 0.09 & -0.65 & .518 \\
\hline Muscularity & 0.21 & 0.26 & 0.81 & .421 & 0.05 & 0.34 & 0.15 & .880 \\
\hline SATAQ-4 & 0.47 & 0.20 & 2.32 & .020 & -0.94 & 0.27 & -3.50 & $<.001$ \\
\hline Time : Muscularity & 1.17 & 0.85 & 1.38 & .167 & -0.42 & 0.81 & -0.52 & .606 \\
\hline $\begin{array}{l}\text { Time : Muscularity : } \\
\text { SATAO-4 }\end{array}$ & -0.26 & 0.31 & -0.85 & .395 & 0.04 & 0.29 & 0.15 & .882 \\
\hline
\end{tabular}

To further understand the effect of perceived sociocultural pressures on personal body image, SATAQ-4 scores were split into high or low based around a mean of 2.7. We then created two models (one for individuals with high SATAQ-4 scores, and one for low SATAQ-4 scores) using BISS as the dependent variable and time, muscularity, and their interaction as predictors. There were no significant effects for individuals with high SATAQ-4 scores, but for individuals with low SATAQ-4 scores (less perceived pressure), there was a significant main effect of muscularity $(\beta=-0.84, S E=$ $0.39, p=.029$ ). This suggests that those who reported low pressure/desire for muscularity had decreased BISS scores (less appearance satisfaction) in both muscularity conditions (see Fig 6). 


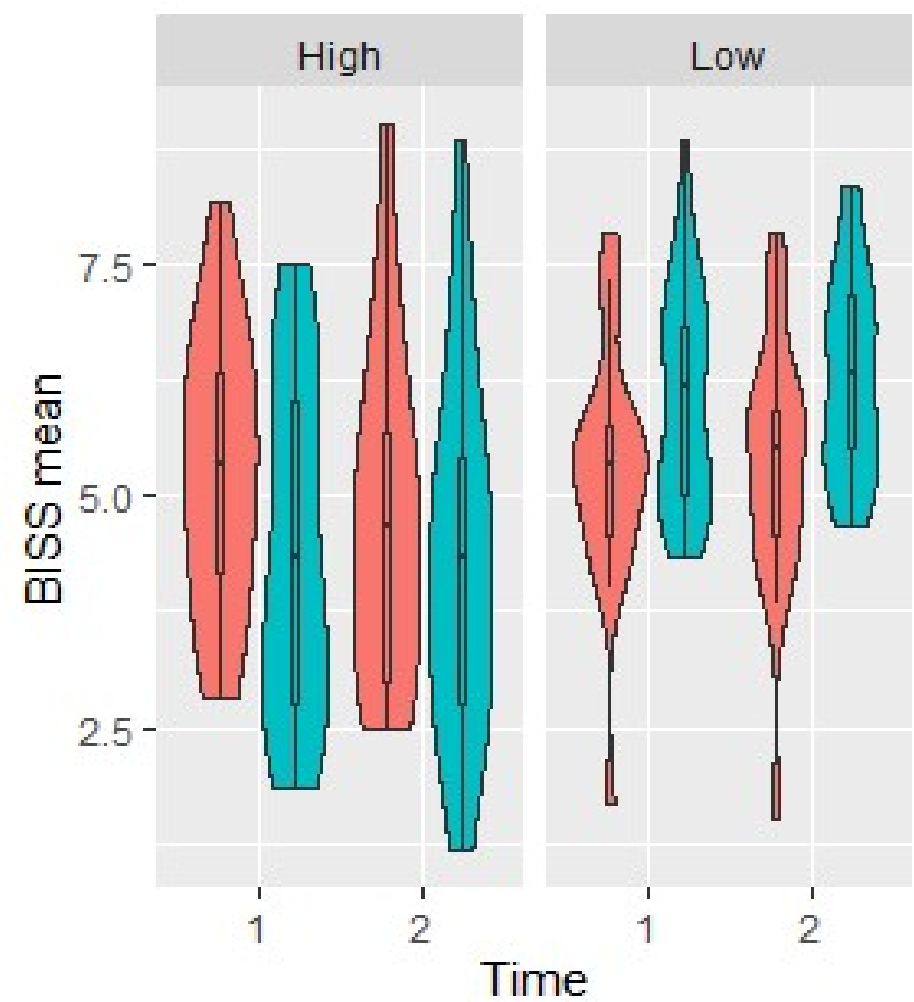

Muscularity condition

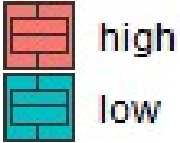

Figure 64. Violin plot showing mean BISS scores for high (left) and low (right) SATAQ-4 pre-and post-manipulation for high (red) and low (blue) muscularity conditions.

\section{Effect of drive for muscularity on muscularity preferences and body image}

The same models as above were used to determine if drive for muscularity measured by the DMS influences muscularity preferences or personal body image after viewing high or low muscle mass images. There was a significant effect of DMS (see Table 7). None of the other main effects or interactions were significant. This suggests that DMS independently influenced muscularity preferences regardless of time or condition (see Fig 7). In the second model, the dependent variable was BISS and the same predictors were used. In this model there were no significant main effects or interactions, suggesting that drive for muscularity does not influence personal body image when viewing images of muscular or non-muscular bodies. We also note that in exploratory analyses (see Supplementary materials) these was also no influence of BMI on these effects.

Table 7. Mixed model effects of time, muscularity, and DMS on muscularity preferences (Model 1), and body satisfaction (Model 2)

Model 1: Muscularity preferences

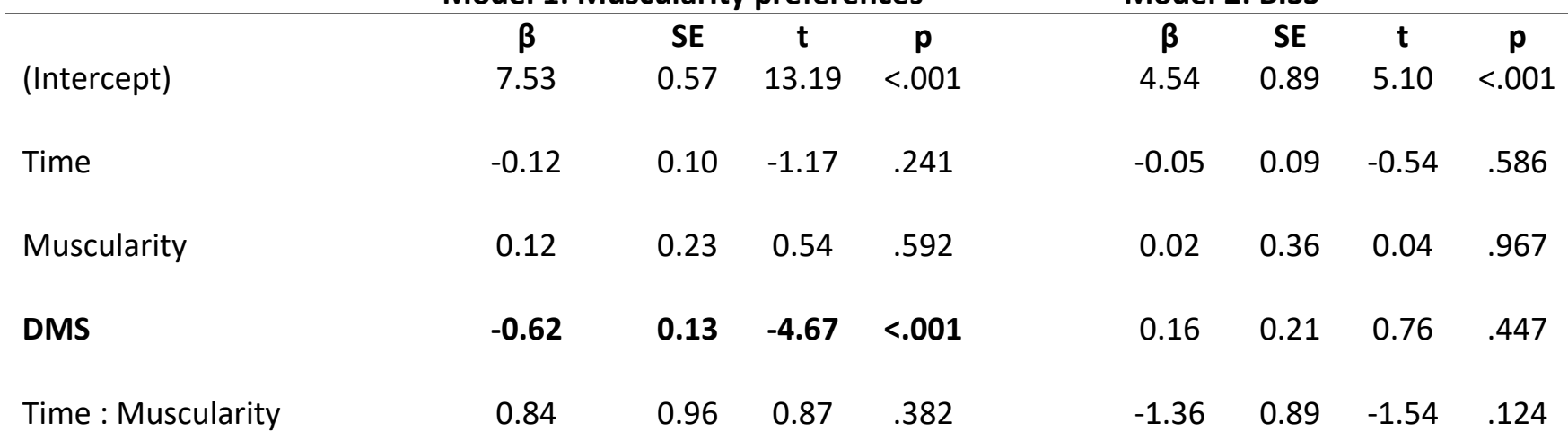




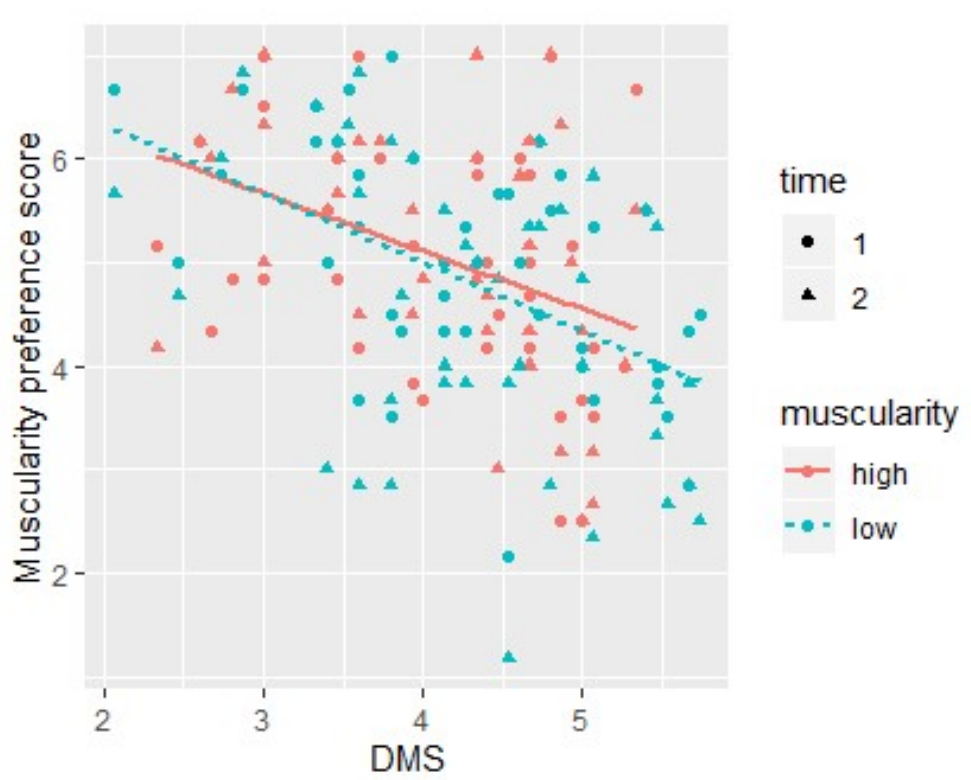

Figure 7. Scatterplot indicating the relationship between DMS and muscularity preference score with information on high (red) and low (blue) muscularity conditions and pre- (circle) and post-(triangle) manipulation. The solid and dotted lines indicate the line of best fit.

\section{Interim Discussion}

The aim of this study was firstly to test whether stimulus type moderated the results seen in Study 1 , and secondly to replicate the finding that SATAQ moderated the experimental impact of viewing low vs high muscularity bodies, while also considering drive for muscularity as another potential moderator, and thirdly to consider body satisfaction as another potential outcome variable. We found again that there was a significant effect of viewing images on muscularity preferences although in this study exposure to non-muscular images decreased muscularity preferences, while exposure to high muscularity images had no significant effect. There was no effect of exposure to either type of image on state body satisfaction. This latter result was unexpected, given that previous studies that exposure to images of 'ideal' bodies decreases body satisfaction (Lorenzen, Grieve, \& Thomas, 2004; Mulgrew \& Cragg, 2015)

In relation to stimulus type, there were no significant differences between viewing CGI or real images on either of the dependent variables. This result allows us to compare studies using different avatar types with the knowledge that it does not significantly influence the results.

In contrast to Study 1, we found no evidence that high perceived sociocultural pressure to obtain an 'ideal' body moderated the experimental effect of viewing images on muscularity preferences. We likewise found no moderating effect of drive for muscularity. We also conducted an exploratory analysis to examine the potential effect of BMI on muscularity preferences and body image, which also found no influence of BMI on the experimental results. 


\section{Discussion}

Overall, the results from these studies demonstrate that, in line with previous research (Boothroyd, Tovee, \& Pollett, 2012; Jacques, submitted), it was possible to alter a person's muscularity preferences through exposure to images of muscular or non-muscular bodies. In Study 1 we found that exposure to muscular or non-muscular bodies could alter an individual's muscularity preferences based on what they had seen using the same technique as Boothroyd et al. (2012), and Robinson and Kirkham (2014), confirming both that the technique can be effective and the overall framework of this study was apt to induce this effect. In Study 2 we found that exposure to non-muscular images decreased muscularity preferences; however, we found exposure to high muscularity images had no significant effect, and there was no effect of exposure to either type of body on body satisfaction. Because both studies used identical setup and were performed in the same manner, this discrepancy suggests that the high muscularity images interacted differently with the participants in study 2 to influence muscularity preferences than the low muscularity images. As gender had no significant effect on changes in muscularity preferences in Study 1, we must conclude that it is not the gender of participants in Study 2 which is the driving factor behind this difference.

A possible explanation for this is that the high muscularity images in the manipulation task possessed similar muscle mass to the high muscularity images in the preference task and, as is explained below, the participants in Study 2 had a previous bias towards the high muscularity image which would potentially limit the impact of exposure to this body type.

Although the high muscle mass images were rated prior to this study for muscularity, they may have been considered by participants to be an average level of muscularity compared to the hyper-muscular figures seen in the media (Pope, Olivardia, Gruber, \& Borowiecki, 1999), as they were within a healthy, obtainable range of muscle mass. Therefore, these images may not have been muscular enough to increase participants' preferences significantly.

Alternatively, the high muscularity images may have been too muscular, and participants did not feel that the high muscularity body was desirable or realistically attainable as they were at the upper limit of healthy muscularity. Therefore, these bodies may be significantly more muscular than participants' own bodies or their peers' bodies. Matthews et al. (2016) suggests that bodies which are considered unrealistic and unobtainable do not influence body satisfaction as participants are aware that they cannot safely obtain the same body. This, however, does not offer an explanation for why participant's muscularity preferences did not change after exposure to these bodies.

As mentioned above, mean muscularity preference pre-manipulation in Study 2 was for the more muscular body, and even the decreased muscularity preference scores slightly preferred the muscular body. Therefore, this suggests that given participants already expressed a preference for the high muscularity body, exposure to bodies with similar muscle mass did not increase preferences for this body type, but exposure to the low muscularity body decreased muscularity preferences as participants did not already prefer this body type.

There are various external factors which might have influenced the exposure effect, such as previous exposure to muscular and non-muscular bodies, and what is being asked of participants. In a study exploring general health perceptions, participants significantly underestimated the weight status of overweight and obese individuals as having a healthy weight (Oldham \& Robinson, 2015), indicating that real life exposure to bodies can influence our perceptions. However, exposure to 
overweight or obese bodies shifting perceptions of health (Oldham \& Robinson, 2015; Robinson \& Kirkham, 2014) does not mean that individuals indicate a preference for these body types. Rating a body as having a healthy weight and having a desire to obtain that body are two separate ratings which cannot be assumed to be equivalent, but it is possible that a similar effect is in play in the current study. Since the current study asked participants to choose which body they preferred, it is unclear whether preference for muscular bodies is related to desire to obtain a similar level of muscularity, or if it is an aesthetic preference. Future research should ensure to distinguish between these when instructing participants.

Grossbard et al. (2011) found that college men's ideal body was significantly more muscular but not significantly thinner, suggesting that, while muscularity was desirable, men were not always wholly dissatisfied with their body, and that thin bodies without high muscularity may also be desirable. In a qualitative study, men defined their ideal body as muscular, lean, and tall (Ridgeway \& Tylka, 2005); however, while muscularity was emphasised it was not the exclusive focus of the ideal body. Generally, men described the ideal body as 'not too big' but 'not too scrawny', suggesting that a hyper-muscular physique is not necessarily the main concern when men consider their bodies, and that being lean is also considered desirable. The study also found that extremes of body composition were considered most undesirable (i.e. too 'skinny' or too 'fat'). This could explain why men did not experience a significant increase or decrease in personal body satisfaction, as only extremely small or large bodies would be considered undesirable.

In Study 1, perceived sociocultural pressure was found to predict changes in muscularity preferences in both genders. Specifically, males who were more dissatisfied with their bodies were found to be more susceptible to exposure to muscular bodies, while the opposite was true in females. This suggests that influences from peers is a significant factor in adolescent body image. This is supported by Kenny et al. (2017) who found in a qualitative study that adolescents felt that their peers were a significantly negative influence on their body image and they experienced pressure to conform to appearance norms. Study 2, however, found no such effect, although we note that state body satisfaction may have decreased after exposure in both conditions due to high desirability of both lean and muscular bodies. As such, pressure from family, peers, and the media may concern becoming leaner as well as becoming more muscular. Furthermore, as the bodies were viewed from the third person perspective, there may have been an element of social comparison involved as individuals compared the body before them to their own body (Preston \& Ehrsson, 2014). Young men have reported comparing themselves to idealised images (Morrison, Kalin, \& Morrison, 2004; Mulgrew \& Cragg, 2015), and engaging in attractiveness and weight comparisons with peers and celebrities has been found to be a precursor to BID (Ho, Lee, \& Liao, 2016). As such, sociocultural pressure and social comparison may represent two elements of the same construct and it is unclear whether perceived sociocultural pressures reported in this study were relating to direct comments or social comparison with others. Future research should seek to explore the relationship between social comparison and sociocultural pressure in young men. However, it is clear from the results of the study that perceived sociocultural pressure (whether direct or indirect) does influence body satisfaction after viewing desirable body types, and future research should endeavour to explore this relationship further.

Drive for muscularity is thought to develop from long-term exposure to muscular bodies (Cramblitt \& Pritchard, 2013; Thornborrow, Onwuegbusi, Mohamed, Boothroyd, \& Tovee, 2020), and the results from Study 2 suggest that short-term exposure may not be enough to alter the effects of 
long-term exposure and internalisation of the muscular ideal as there was no interaction between drive for muscularity and other variables. This finding is not in keeping with previous research which employed similar methods and found no effect of drive for muscularity (Jacques, submitted), indicating that the relationship between drive for muscularity and muscularity preferences is complex. The results of the current study indicate that drive for muscularity is a strong predictor of preferences for a muscular body, and that exposure to 24 high or low muscle mass images is not sufficient to significantly increase or decrease this preference.

A key limitation to note across both studies is that firstly, CGI and real images were not matched for amount of visible muscle mass in high/low muscularity conditions, or on other superficial information such as height, ethnicity, or body hair. The images presented were intended to only provide visual differences along a (healthy) muscularity spectrum, and therefore all images had relatively low body fat percentage. However, the effect of this is that even in the low muscularity conditions, a certain level of muscular definition will be visible. As a result, the low muscularity images may have inadvertently been considered to have a desirable level of muscularity. Additionally, the high muscularity real images were visibly less muscular than the high muscularity CGI images, potentially acting as a neutral category rather than high muscularity. Future research should consider the perceived level of muscularity of the images and strive to ensure that the high-muscularity images contain a high amount of visible muscle mass which is above the average seen in everyday life. Additionally, images across conditions should be matched for superficial features such as body hair and ethnicity to eliminate any effects of these on the strength of the manipulation.

Body image in men is complex, and interactions between muscularity and body fat should be explored further in order to understand what types of body are considered desirable by young men. This will also help to expand on the current results which suggest that bodies with low muscularity and low body fat may be considered desirable, as well as bodies with high muscle mass and low body fat.

In conclusion, this paper aimed to determine how muscularity preferences and young men's body image are influenced by exposure to non-muscular or muscular bodies. We found a robust effect of viewing male bodies on preferences for muscularity, although there is some difference between our studies regarding whether participants are perhaps saturated by high muscularity, such that low muscularity may sometimes have more of an effect. Our results, also however, contribute to the ongoing ambiguity regarding the role of pre-existing susceptibility to such effects, and suggest the mechanisms at play in these effects require greater understanding in order to elucidate these inconsistent results. Overall, this study contributes to the understanding of male body image and highlights the complex relationship between muscularity and body image in young men.

\section{References}

Anzures, G., Mondloch, C. J., \& Lackner, C. (2009). Face Adaptation and Attractiveness Aftereffects in 8-Year-Olds and Adults. Child Development, 80(1), 178-191. doi:10.1111/j.14678624.2008.01253.x 
Ata, R. N., Ludden, A. B., \& Lally, M. M. (2007). The effects of gender and family, friend, and media influences on eating behaviours and body image during adolescence. Journal of Youth and Adolescence, 36, 1024-1037. doi:10.1007/s10964-006-9159-x

Bair, C. E., Kelly, N. R., Serdar, K. L., \& Mazzeo, S. E. (2012). Does the internet function like magazines? An exploration of image-focussed media, eating pathology, and body dissatisfaction. Eating Behaviours, 13(4), 398-401. doi:10.1016/j.eatbeh.2012.06.003

Ball, B., \& Dittmar, H. (2011). Does media type matter? The role of identification in adolescent girls' media consumption and the impact of different thin-ideal media on body image. Sex Roles, 65(7), 478-490. doi:10.1007/s11199-011-9964-x

Barlett, C. P., Vowels, C. L., \& Saucier, D. A. (2008). Meta-Analyses of the Effects of Media Images on Men's Body-Image Concerns. Journal of Social and Clinical Psychology, 27(3), 279-310. doi:10.1521/jscp.2008.27.3.279

Barra, J. V., Roberto da Silva, W., Maroco, J., \& Campos, J. A. (2019). Cross-cultural adaptation of the Sociocultural Attitudes Towards Appearance Scale-4 (SATAQ-4) applied to university students. Public Health Notebooks, 25(5). doi:10.1590/0102-311x00170218

Bates, D., Maechler, M., Bolker, B., \& Walker, S. (2015). Fitting linear mixed-effects models using Ime4. Journal of Statistical Software, 67(1), 1-48. doi:10.18637/jss.v067.i01

Becker, C. B., Verzijl, C. L., Kilpela, L. S., Wilfred, S. A., \& Stewart, T. (2019). Body image in adult women: Associations with health behaviours, quality of life, and functional impairment. Journal of Health Psychology, 24(11), 1536-1547. doi:10.1177/1359105317710815

Boothroyd, L. G., Jucker, J.-L., Thornborrow, T., Barton, R. A., Burt, D. M., Evans, E. H., . . Tovee, M. J. (2019). Television consumption drives perceptions of female body attractiveness in a population undergoing technological transition. Journal of Personality and Social Psychology. doi:10.1037/pspi0000224

Boothroyd, L. G., Jucker, J.-L., Thornborrow, T., Barton, R., Burt, D. M., Evans, E. H., . . Tovee, M. J. (2020). Television consumption drives perceptions of female body attractiveness in a population undergoing technological transition. Journal of Personality and Social Psychology. doi:10.1037/pspi0000224

Boothroyd, L. G., Jucker, J.-L., Thronborrow, T., Jamieson, M. A., Burt, D. M., Barton, R. A., . . Tovee, M. J. (2016). Television exposure predicts body size ideals in rural Nicaragua. British Journal of Psychology, 107(4), 752-767. doi:10.1111/bjop.12184

Boothroyd, L. G., Tovee, M. T., \& Pollett, T. (2012). Visual diet versus associative learning as mechanisms of change in body size preferences. PLOS ONE, 7(11), e48691. doi:10.1371/journal.pone.0048691

Bornioli, A., Lewis-Smith, H., Smith, A., Slater, A., \& Isabelle, B. (2019). Adolescent body dissatisfaction and disordered eating: Predictors of later risky health behaviours. Social Science \& Medicine, 238, 112458. doi:Adolescent body dissatisfaction and disordered eating: Predictors of later risky health behaviours

Cafri, G., Yamamiya, Y., Brannick, M., \& Thompson, J. K. (2006). The influence of sociocultural factors on body image: A meta-analysis. Clinical Psychology, 12(4). doi:10.1093/clipsy.bpi053 
Cash, T. F., Fleming, E. C., Alindogan, J., Steadman, L., \& Whitehead, A. (2002). Beyond Body Image as a Trait: The Development and Validation of the Body Image States Scale. Eating Disorders, 10(2), 103-113. doi:10.1080/10640260290081678

Cash, T. F., Morrow, J. A., Hrabosky, J. I., \& Perry, A. A. (2004). How Has Body Image Changed? A Cross-Sectional Investigation of College Women and Men From 1983 to 2001. Journal of Consulting and Clinical Psychology, 72(6), 1081-1089. doi:10.1037/0022-006X.72.6.1081

Cazzato, V., Mian, E., Mele, S., Tognana, G., Todisco, P., \& Urgesi, C. (2016). The effects of body exposure on self-body image and esthetic appreciation in anorexia nervosa. Experimental Brain Research, 234, 695-709.

Cazzato, V., Siega, S., \& Urgesi, C. (2012). "What women like": influence of motion and form of esthetic body perception. Frontiers in Psychology, 3, 235. doi:10.3389/fpsyg.2012.00235

Cordes, M., Vocks, S., Dusing, R., Bauer, A., \& Waldorf, M. (2016). Male body image and visual attention towards oneself and other men. Psychology of Men \& Masculinity, 17(3), 243-254. doi:10.1037/men0000029

Cornelissen, K. K., McCarty, K., Cornelissen, P. L., \& Tovee, M. J. (2017). Body size estimation in women with anorexia nervosa and healthy controls using 3D avatars. Scientific Reports, 7(15883). doi:10.1038/s41598-017-15339-z

Cramblitt, B., \& Pritchard, M. (2013). Media's influence on the drive for muscularity in undergraduates. Eating Behaviours, 14(4), 441-446. doi:10.1016/j.eateh.2013.08.003

Dakanalis, A., Zanetti, A. M., Riva, G., Colmegna, F., Volpato, C., Madeddu, F., \& Clerici, M. (2015). Male body dissatisfaction and eating disorder symptomatology: Moderating variables among men. Journal of Health Psychology, 20(1), 80-90. doi:10.1177/1359105313499198

Dawson, N., \& Hammer, J. H. (2020). No pain, no gains: Conformity to masculine norms, body dissatisfaction, and exercise dependence. Psychology of Men \& Masculinity, 21(3), 430-440. doi:10.1037/men0000243

De Jesus, A. Y., Ricciardelli, L. A., Frisen, A., Smolak, L., Yager, Z., Fuller-Tyszkiewicz, M., . . Gattario, K. H. (2015). Media Internalisation and Conformity to Traditional Masculine Normas in Relation to Body Image Concerns Among Men. Eating Behaviours, 18, 137-142. doi:10.1016/j.eatbeh.2015.04.004

DeBlaere, C., \& Brewster, M. E. (2017). A Confirmation of the Drive for Muscularity Scale with Sexual Minority Men. Psychology of Sexual Orientation and Gender Diversity, 4(2), 227-232. doi:10.1037/sgd0000224

Dion, J., Blackburn, M.-E., Auclair, J., Laberge, L., Veillette, S., Gaudreault, M., . . . Touchette, E. (2015). Development and aetiology of body dissatisfaction in adolescent boys and girls. International Journal of Adolescence and Youth, 20(2), 151-166. doi:10.1080/02673843.2014.985320

Duchin, O., Marin, C., Mora-Plazas, M., Mendes de Leon, C., Lee, J. M., Baylin, A., \& Villamor, E. (2015). A prospective study of body image dissatisfaction and BMI change in school-age children. Public Health Nutrition, 18(2), 322-328. doi:10.1017/S1368980014000366 
Edwards, C., Molnar, G., \& Tod, D. (2017). Searching for masculine capital: Experiences leading to high drive for muscularity in men. Psychology of Men and Masculinities, 18(4), 361-371. doi:10.1037/t39771-000

Evans, E. H. (2012). Biopsychosocial factors in body dissatisfaction and disordered eating attitudes amongst preadolescent girls: cross-sectional and longitudinal perspectives. Durham theses, Durham University. Retrieved from http://etheses.dur.ac.uk/5930/

Evans, E. H., Adamson, A. J., Basterfield, L., Le Couteur, A., Reilly, J., Reilly, J. J., \& Parkinson, K. N. (2017). Risk factors for eating disorder symptoms at 12 years of age: A 6-year longitudinal cohort study. Appetite, 108, 12. doi:10.1016/j.appet.2016.09.005

Ferrer-Garcia, M., \& Gutierrez-Maldonado, J. (2012). The use of virtual reality in the study, assessment, and treatment of body image in eating disorders and nonclinical samples: A review of the literature. Body Image, 9(1), 1-11. doi:10.1016/j.bodyim.2011.10.001

Frith, H., \& Gleeson, K. (2004). Clothing and Embodiment: Men Managing Body Image and Appearance. Psychology of Men \& Masculinity, 5(1), 40-48. doi:10.1037/1524-9220.5.1.40

Galioto, R., \& Crowther, J. H. (2013). The effects of exposure to slender and muscular images on male body dissatisfaction. Body Image, 10(4), 566-573. doi:10.1016/j.bodyim.2013.07.009

Gattario, K. H., Frisen, A., Fuller-Tyszkiewicz, M., Ricciardelli, L. A., Diedrichs, P. C., Yager, Z., . . Smolak, L. (2015). How Is Men's Conformity to Masculine Norms Related to Their Body Image? Masculinity and Muscularity Across Western Countries. Psychology of Men \& Masculinity, 16(3), 337-347. doi:10.1037/a0038494

Grossbard, J. R., Neighbors, C., \& Larimer, M. E. (2011). Perceived norms for thinness and muscularity among college students: What do men and women really want? Eating Behaviours, 12, 192-199. doi:10.1016/j.eatbeh.2011.04.005

Groves, V., Cornelissen, P., McCarty, K., Mohamed, S., Maalin, N., Tovee, M. J., \& Cornelissen, K. (2019). How does variation in the body composition of both stimuli and participant modulate self-estimates of men's body size. Frontiers in Psychology, 10, 720. doi:10.3389/fpsyt.2019.00720

Harrison, K., \& Bond, B. J. (2007). Gaming magazines and the drive for muscularity in preadolescent boys: A longitudinal examination. Body Image, 4(3), 269.

Ho, S. S., Lee, E. E., \& Liao, Y. (2016). Social Network Sites, Friends, and Celebrities: The Roles of Social Comparison and Celebrity Involvement in Adolescents' Body Image Dissatisfaction. Social Media + Society, 2(3). doi:10.1177/2056305116664216

Jones, D. C., \& Crawford, J. K. (2005). Adolescent Boys and Body Image: Weight and Muscularity Concerns as Dual Pathways to Body Dissatisfaction. Journal of Youth and Adolescence, 34(6), 629-636. doi:10.1007/s10964-005-8951-3

Juarascio, A. S., Forman, E. M., Timko, C. A., Herbert, J. D., Butryn, M., \& Lowe, M. (2011). Implicit internalization of the thin ideal as a predictor of increases in weight, body dissatisfaction, and disordered eating. Eating Behaviours, 12(3), 207-213. doi:10.1016/j.eatbeh.2011.04.004

Jung, J. (2011). Advertising Images of Men: Body Size and Muscularity of Men Depicted in Men's Health Magazine. Journal of Global Fashion Marketing, 2, 181-187. doi:10.1080/20932685.2011.10593096 
Kenny, U., O'Malley-Keighran, M.-P., Molcho, M., \& Kelly, C. (2017). Peer influences on adolescent body image: Friends or Foes? Journal of Adolescent Research, 32(6), 768-799. doi:10.1177/0743558416665478

Klimek, P., Murray, S. B., Brown, T., Gonzales, M., \& Blashill, A. J. (2018). Thinness and muscularity internalization: Associations with disordered eating and muscle dysmorphia in men. International Journal of Eating Disorders, 51(4). doi:10.1002/eat.22844

Lai, C.-M., Mak, K.-K., Pang, J. S., Fong, S. S., Ho, R. C., \& Guldan, G. S. (2013). The associations of sociocultural attitudes towards appearance with body dissatisfaction and eating behaviors in Hong Kong adolescents. Eating Behaviours, 14(3), 320-324. doi:10.1016/j.eatbeh.2013.05.004

Lane, B. R., Mulgrew, K. E., White, M. J., \& Mahar, D. (2019). Effects of the Muscular Ideal on Appearance-Related Attentional Biases in Men. Psychology of Men \& Masculinities, 20(3), 394-405. doi:10.1037/men0000170

Lavender, J. M., Brown, T. A., \& Murray, S. B. (2017). Men, muscles, and eating disorders: An overview of traditional and muscularity-oriented disordered eating. Current Psychiatry Reports, 19, 32. doi:10.1007/s11920-017-0787-5

Lawler, M., \& Nixon, E. (2011). Body dissatisfaction among adolescent boys and girls: The effects of body mass, peer appearance culture and internalisation of appearance ideals. Journal of Youth and Adolescence, 40, 59-71. doi:10.1007/s10964-009-9500-2

Lawler, M., \& Nixon, E. (2011). Body Dissatisfaction Among Adolescent Boys and Girls: The Effects of Body Mass, Peer Appearance Culture and Internalization of Appearance Ideals. Journal of Youth and Adolescence, 40(1), 59-71. doi:10.1007/s10964-009-9500-2

Litt, D., \& Dodge, T. (2008). A longitudinal investigation of the Drive for Muscularity Scale: Predicting use of performance enhancing substances and weightlifting among males. Body Image, 5(4), 346-351. doi:10.1016/j.bodyim.2008.04.002

Lorenzen, L. A., Grieve, F. G., \& Thomas, A. (2004). Exposure to muscular male models decreases men's body satisfaction. Sex Roles, 51. doi:10.1007/s11199-004-0723-0

Matthews, N. L., Lynch, T., \& Martins, N. (2016). Real ideal: investigating how ideal and hyper-ideal video game bodies affect men and women. Computers in Human Behaviour, 59, 155-164. doi:10.1016/j.chb.2016.01.026

McCabe, M. P., \& Ricciardelli, L. A. (2003). Sociocultural influences on body image and body changes among adolescent boys and girls. Journal of Social Psychology, 143(1), 5-26. doi:10.1080/00224540309598428

McCreary, D. R., \& Sasse, D. (2000). An exploration of the drive for muscularity in adolescent boys and girls. Journal of American College Health, 48(6), 297-304. doi:10.1080/07448480009596271

McCreary, D. R., Sasse, D. K., Saucier, D. M., \& Dorsch, K. D. (2004). Measuring the Drive for Muscularity: Factorial Validity of the Drive for Muscularity Scale in Men and Women. Psychology of Men and Masculinities, 5(1), 49-58. doi:10.1037/1524-9220.5.1.49

McPherson, K. E., McCarthy, P., McCreary, D. R., \& McMillan, S. (2010). Psychometric evaluation of the Drive for Muscularity Scale in a community-based sample of Scottish men participating 
in an organized sporting event. Body Image, 7(4), 368-371.

doi:10.1016/j.bodyim.2010.06.001

Mo, J. J., Cheung, K. W., Gledhill, L. J., Pollet, T. V., Boothroyd, L. G., \& Tovee, M. J. (2014). Perceptions of female body size and shape in China, Hong Kong, and the United Kingdom. Cross-Cultural Research, 48(1), 78-103. doi:10.1177/1069397113510272

Morrison, D., Wang, H., Hahn, A. C., Jones, B. C., \& DeBruine, L. M. (2017). Predicting the reward value of faces and bodies from social perception. PLoS one, 12(9), e0185093.

Morrison, T. G., \& Halton, M. (2009). Buff, tough, and rough: Representations of muscularity in action motion pictures. The Journal of Men's Studies, 17(1), 57-74. doi:10.3149/jms.1701.57

Morrison, T. G., Kalin, R., \& Morrison, M. A. (2004). Body image evaluation and body image investment among adolescents: A test of sociocultural and social comparison theories. Adolescence, 39(155), 571-592.

Mulgrew, K. E., \& Cragg, D. N. (2015). Age differences in body image responses to idealised male figures in music television. Journal of Health Psychology. doi:10.1177/1359105315616177

NHS. (2018, November 5). BMI healthy weight calculator. Retrieved from NHS: https://www.nhs.uk/live-well/healthy-weight/bmi-calculator/

Oldham, M., \& Robinson, E. (2015). Visual weight misperceptions; overweight looks like a 'healthy weight'. Appetite, 87, 371. doi:10.1016/j.appet.2014.12.103

Pope, H. G., Olivardia, R., Gruber, A., \& Borowiecki, J. (1999). Evolving ideals of male body image as seen through action toys. International Journal of Eating Disorders, 26(1), 65-72. doi:10.1002/(SICI)1098-108X(199907)26:1<65::AID-EAT8>3.0.CO;2-D

Preston, C., \& Ehrsson, H. H. (2014). Illusory Changes in Body Size Modulate Body Satisfaction in a Way That Is Related to Non-Clinical Eating Disorder Psychopathology. PLoS ONE, 9, e85773. doi:10.1371/journal.pone.0085773

Pritchard, M., Parker, C., \& Nielsen, A. (2011). What predicts drive for muscularity in college students? Eating Behaviours, 12(3), 228-231. doi:10.1016/j.eatbeh.2011.04.002

R Core Team. (2020). R: A language and environment for statistical computing. R Foundation for Statistical Computing. Vienna, Austria. Retrieved from http://www.R-project.org/

Ricciardelli, L. A., \& McCabe, M. P. (2001). Dietary restraint and negative affect as mediators of body dissatisfaction and bulimic behaviour in adolescent girls and boys. Behaviour Research and Therapy, 39(11), 1317-1328. doi:10.1016/S0005-7967(00)00097-8

Ridgeway, R. T., \& Tylka, T. L. (2005). College men's perceptions of ideal body composition and shape. Psychology of Men \& Masculinities, 6(3), 209-220. doi:10.1037/1524-9220.6.3.209

Robinson, E., \& Kirkham, T. C. (2014). Is he a healthy weight? Exposure to obesity changes perception of the weight status of others. International Journal of Obesity, 38, 663-667. doi:10.1038/ijo.2013.154

Schaefer, L. M., Burke, N. L., Thompson, K. J., Dedrick, R. F., Heinberg, L. J., Calogero, R. M., . . Nerini, S. V. (2015). Development and validation of the Sociocultural Attitudes Towards 
Appearance Questionnaire-4 (SATAQ-4). Psychological Assessment, 27(1), 54-67.

doi:10.1037/a0037917

Spitzer, B. L., Henderson, K. A., \& Zivian, M. T. (1999). Gender differences in population versus media body sizes: A comparison over four decades. Sex Roles, 40(7-8), 545-565. doi:10.1023/A:1018836029738

Stanford, J. N., \& McCabe, M. P. (2005). Sociocultural influences on adolescent boys' body image and body change strategies. Body Image, 2(2), 105-113. doi:10.1016/j.bodyim.2005.03.002

Stice, E., \& Whitenton, K. (2002). Risk factors for body dissatisfaction in adolescent girls: A longitudinal investigation. Developmental Psychology, 38(5), 669-678. doi:10.1037/00121649.38.5.669

Stice, E., Spangler, D., \& Agras, W. S. (2001). Exposure to media-portrayed thin-ideal images adversely affects vulnerable girls: A longitudinal experiment. Journal of Social and Clinical Psychology, 20(3), 270-288. doi:10.1521/jscp.20.3.270.22309

Swami, V., Frederick, D. A., Aavik, T., Alcalay, L., Allik, J., Anderson, D., . . Halberstadt, J. (2010). The attractive female body weight and female body dissatisfaction in 26 countries across 10 world regions: Results of the International Body Project I. Psychology \& Social Psychology Bulletin, 36(3), 309-325. doi:10.1177/0146167209359702

Tan, Y., Shaw, P. C., \& Ko Kim, K. (2013). The construction of masculinity: A cross-cultural analysis of men's lifestyle magazine advertisments. Sex Roles, 69, 237-249. doi:10.1007/s11199-0130300-5

Thornborrow, T., Onwuegbusi, T., Mohamed, S., Boothroyd, L. G., \& Tovee, M. J. (2020). Muscles and the Media: A natural experiment across cultures in men's body image. Frontiers in Psychology, 11, 495. doi:10.3389/fpsyg.2020.00495 


\section{Supplemental Material}

\section{Exploratory analysis: Influence of BMI on muscularity preferences and body image}

In some previous studies, BMI has been found to be related to muscularity preferences and body image, while others have found no effect of BMI. We therefore conducted a mixed effect linear model in order to explore the influence of BMI on muscularity scores and body image in young men.

The first model used muscularity preference as the dependent variable, and time (pre/post manipulation), muscularity (high/low muscle mass images), BMI, and their interactions as predictors. There was a significant main effect of time, and a significant interaction between time and BMI (see Table 8). However, there was no 3-way interaction between time, muscularity, and BMI, indicating that differences in BMI groups were not due to the experimental manipulation.

Table 8. Mixed model effects of time, muscularity, and BMI on muscularity preferences (Model 1), and body satisfaction (Model 2)

Model 1: Muscularity preferences

\begin{tabular}{|c|c|c|c|c|c|c|c|c|}
\hline & $\beta$ & SE & $\mathbf{t}$ & p & $\beta$ & SE & $t$ & p \\
\hline (Intercept) & 4.00 & 0.85 & 4.73 & $<.001$ & 7.21 & 1.12 & 6.41 & $<.001$ \\
\hline Time & 1.43 & 0.57 & 2.50 & .012 & -0.49 & 0.58 & -0.84 & .399 \\
\hline Muscularity & 2.58 & 1.69 & 1.53 & .127 & -5.68 & 2.25 & -2.53 & .012 \\
\hline BMI & 0.04 & 0.04 & 1.10 & .270 & -0.08 & 0.05 & -1.79 & .073 \\
\hline Time : & 0.54 & 1.15 & 0.47 & .637 & 1.37 & 1.16 & 1.18 & .237 \\
\hline \multicolumn{9}{|l|}{ Muscularity } \\
\hline Time : BMI & -0.07 & 0.03 & -2.79 & .005 & 0.02 & 0.02 & 0.77 & .444 \\
\hline $\begin{array}{l}\text { Muscularity : } \\
\text { BMI }\end{array}$ & -0.10 & 0.07 & -1.40 & .163 & 0.24 & 0.10 & 2.55 & .011 \\
\hline Time : & -0.01 & 0.05 & -0.11 & .913 & -0.07 & 0.05 & -1.43 & .153 \\
\hline Muscularity : & & & & & & & & \\
\hline
\end{tabular}

The second model used BISS as the dependent variable with the same predictors as previous. There was a significant main effect of muscularity and a significant interaction between muscularity and BMI (see Table 8), however, as there was no 3-way interaction between time, muscularity, and $\mathrm{BMI}$, we can conclude that there was no effect of BMI on the experimental result. 